\title{
Experimental study on the influence of recycled aggregates on the mechanical properties of concrete
}

\author{
LI Chuangui ${ }^{1}$, ZHAO Hongkui $^{1}$, WU Jianfeng ${ }^{1}$, LI Xiangang ${ }^{1}$, ZHANG Ya $^{1}$ \\ ${ }^{1}$ SHANDONG LUQIAO GROUP CO., LTD, 250014, Jinan, Shandong, China
}

\begin{abstract}
Construction solid waste has become an important environmental pollution source in the city, and the treatment and application of construction solid waste has become the focus of attention. Construction waste recycled aggregates have defects such as high water absorption and micro cracks, which affect its extensive application. In order to improve the utilization rate of recycled aggregates, the influence of different replacement rates of recycled aggregates on the mechanical properties of concrete is studied in this paper. The results show that with the increase of replacement rate of recycled aggregates, the 3-day, 7day and 28-day compressive strength, splitting strength and cohesive force of concrete decrease gradually, but the mechanical properties of concrete decrease slowly at 3 days and 7 days, and decrease obviously at 28 days. Moreover, with the increase of replacement rate of recycled aggregates, the decline trend of mechanical properties is not obvious. Compared with natural aggregate concrete, the 28-day compressive strength, splitting strength and cohesive force of $100 \%$ recycled aggregate concrete are reduced by $16.1 \%$, $20.1 \%$ and $18.1 \%$ respectively, but the mechanical properties meet the requirements of C30 concrete, which provides a reference for engineering application.
\end{abstract}

\section{Introduction}

In recent years, with the rapid economic development of China and the acceleration of demolition of old buildings, the total construction waste increases. If waste concrete can be recycled and recycled, it can be used for construction industry, highway transportation and railway traffic construction. That will consume a lot of recycled aggregates, which has important ecological and economic significance [1-4]. For a long time, many researchers and engineers have studied the application of recycled aggregates. Matthias found that when the aggregates are saturated with water, water channels will be formed by the free water outside the aggregates and the free water inside the aggregates. It will weaken the bonding surface of aggregates and cement slurry and affect the working performance of concrete [5]. Gholamreza studied a new mix proportioning method that recycled aggregate concrete is treated as a composite material with two components consisting of residual mortar and natural aggregates, in which the creep and shrinkage of recycled concrete are equivalent to that of natural concrete, which makes recycled concrete more valuable in engineering application [6]. Through the experimental study, Cheng et al. found that when the replacement rate of recycled coarse aggregates is $50 \%$, its frost resistance is close to that of ordinary concrete, and is better than other substitution rate, which provides a technical reference for engineering application [7]. Li et al. studied the key influencing factors of the flexural strength of recycled concrete considering various factors, and found that the replacement rate of recycled coarse aggregates and the gradation of coarse aggregates are the main influencing factors of the flexural strength of recycled concrete [8]. Folino et al. studied the failure and mechanical properties of recycled aggregate concrete with recycled aggregates of different ratio under different load scenarios by the experimental method, and they found that recycled aggregates have a greater porosity in comparison with natural aggregates, and recycled aggregate concretes have a lower density [9]. The above research shows that recycled aggregate concrete has a certain application value in engineering. However, recycled aggregate concrete has not been systematically studied and utilized. In this paper, recycled aggregate concrete is taken as the research object, and recycled coarse aggregates are used to replace natural coarse aggregates. The influence of mechanical properties of concrete with different replacement rates of recycled aggregates is tested, which provides theoretical support for the engineering application of recycled aggregate concrete in construction engineering and highway engineering.

\section{Experimental materials and method}

\subsection{Experimental materials}

The main components of concrete include cement, natural aggregates, recycled aggregates and water. Ordinary portland cement (Grade 42.5, Jidong Cement

\footnotetext{
* Corresponding author: 56928514@qq.com
} 
Jingyang Co., Ltd) was adopted in the experiment. The fine material used in the test was river sand with fineness modulus of 2.89. The recycled aggregates were obtained from a construction waste after crushing and screening. The physical properties of natural sands, recycled aggregates (RFA) and natural aggregates (NCA) were tested in accordance with GB/T 14684-2011 and GB/T 14685-2011 crushed stone and pebble for construction respectively, and the results are shown in Table 1 . The natural aggregate and recycled aggregate concrete are composed of crushed stones with particle sizes of 2.36$4.75 \mathrm{~mm}, 4.75-9.5 \mathrm{~mm}, 9.5-19.0 \mathrm{~mm}$ and $19.0-26.5 \mathrm{~mm}$, which are mixed with mass percentages of $3 \%, 37 \%$, $55 \%$ and $5 \%$. The proportion of natural aggregate and recycled aggregate concrete is shown in Table 2 , and the replacement rates of recycled aggregate are $0,20 \%, 40 \%$, $60 \%, 80 \%$ and $100 \%$ respectively.

Table 1. Properties of natural and recycled aggregates.

\begin{tabular}{ccccc}
\hline Name & $\begin{array}{c}\text { Bulk density } \\
\mathrm{kg} \cdot \mathrm{m}^{-3}\end{array}$ & $\begin{array}{c}\text { Water } \\
\text { absorption }\end{array}$ & $\begin{array}{c}\text { Crushing } \\
\text { value }\end{array}$ & Porosity \\
\hline $\begin{array}{c}\text { Natural } \\
\text { aggregate }\end{array}$ & 2860 & $0.5 \%$ & $5.4 \%$ & $41.5 \%$ \\
$\begin{array}{c}\text { Recycled } \\
\text { aggregate }\end{array}$ & 2390 & $6.9 \%$ & $16.2 \%$ & $47.7 \%$ \\
\hline
\end{tabular}

Table 2. Concrete mix ratio $\left(\mathrm{kg} \cdot \mathrm{m}^{-3}\right)$.

\begin{tabular}{cccccc}
\hline $\begin{array}{c}\text { Type of } \\
\text { concrete }\end{array}$ & cement & sand & $\begin{array}{c}\text { Natural } \\
\text { aggregate }\end{array}$ & $\begin{array}{c}\text { recycled } \\
\text { aggregate }\end{array}$ & water \\
\hline RAC0 & 351 & 596 & 1268 & 0 & 185 \\
RAC20 & 351 & 596 & 1014 & 254 & 188.4 \\
RAC40 & 351 & 596 & 760 & 508 & 191.6 \\
RAC60 & 351 & 596 & 506 & 762 & 195 \\
RAC80 & 351 & 596 & 252 & 1016 & 198.2 \\
RAC100 & 351 & 596 & 0 & 1268 & 201.6 \\
\hline
\end{tabular}

\subsection{Experimental method}

According to the proportioning requirements, each group of raw materials including the aggregate, fine sand, cement was accurately weighed the quality and pushed them into the mixer for premixing to uniform concrete. After 24 hours, the samples prepared by the standard cube sample (100 mm* $100 \mathrm{~mm} * 100 \mathrm{~mm})$ were demoulded and placed in standard environment $\left(20^{\circ} \mathrm{C} \pm 2{ }^{\circ} \mathrm{C}\right)$ to be cured, seeing fig. 1 . After 3 days, 7 days and 28 days, they were taken out and tested. According to the mix proportion, shown in Table 2, the samples of concrete were divided into 6 groups, and each group has three samples. These were used to test 3-day, 7-day and 28-day infinite compressive strength and splitting strength, and infinite compressive strength and splitting strength were test using pressure testing machine (Dye-2000 type). In addition, the internal bond strength of concrete was calculated based on compressive strength and splitting strength.

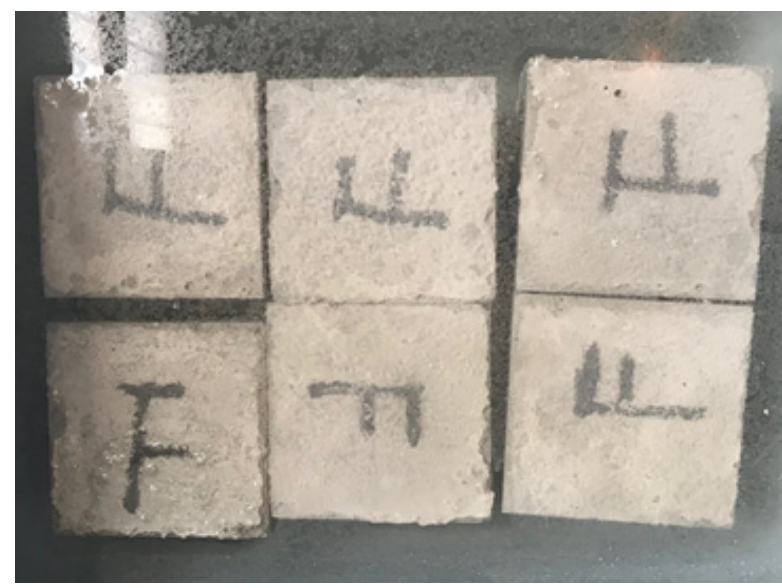

Fig. 1. The concrete samples by the national standard curing method.

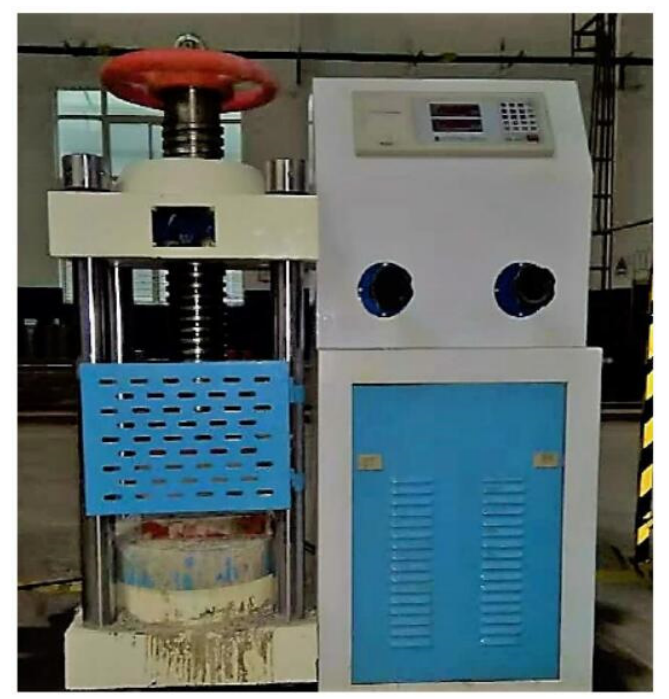

Fig. 2. Pressure testing machine in infinite compressive strength and splitting strength.

\section{Experimental results and analysis}

\subsection{Compressive strength of concrete with different recycled aggregate replacement rates}

Figure 3 shows the 3-day, 7-day and 28-day compressive strength of $\mathrm{C} 30$ concrete with different replacement rates of recycled aggregates. It can be seen from the figure 3 that, according to the experimental design, 3-day, 7-day and 28-day the compressive strength of concrete decrease gradually when the replacement rate of recycled aggregates changes from $0 \%, 20 \%, 40 \%, 60 \%$, $80 \%$ and $100 \%$, but the decreasing rates of 3-day and 7 day compressive strength are slow. Compared with ordinary concrete, the 3-day and 7-day compressive strength decrease by $13.7 \%$ and $12.9 \%$ respectively. The hydration reaction of mixture is not completed completely, and the cement hardening is not formed completely, and the performances of concrete are mainly determined by the characteristics of aggregates. With the increase of age, the 28-day compressive strength increases. Compared with ordinary concrete, the strength 
of $100 \%$ recycled aggregate concrete decreases by $16.1 \%$. This is because with the increase of age, the mortar bond is stronger and the strength increases when the concrete is fully hydrated. However, due to the existence of voids and old mortar, the bond strength of recycled aggregate concrete is weaker, which shows that with the increase of recycled aggregates, 28-day compressive strength is lower. In addition, with the increase of replacement rate of recycled aggregates, for example, from $80 \%$ to $100 \%$, there is little change at 3 day, 7-day and 28-day compressive strength of recycled aggregate concrete. These results show that it is possible to be applied $100 \%$ recycled aggregate concrete in engineering application.

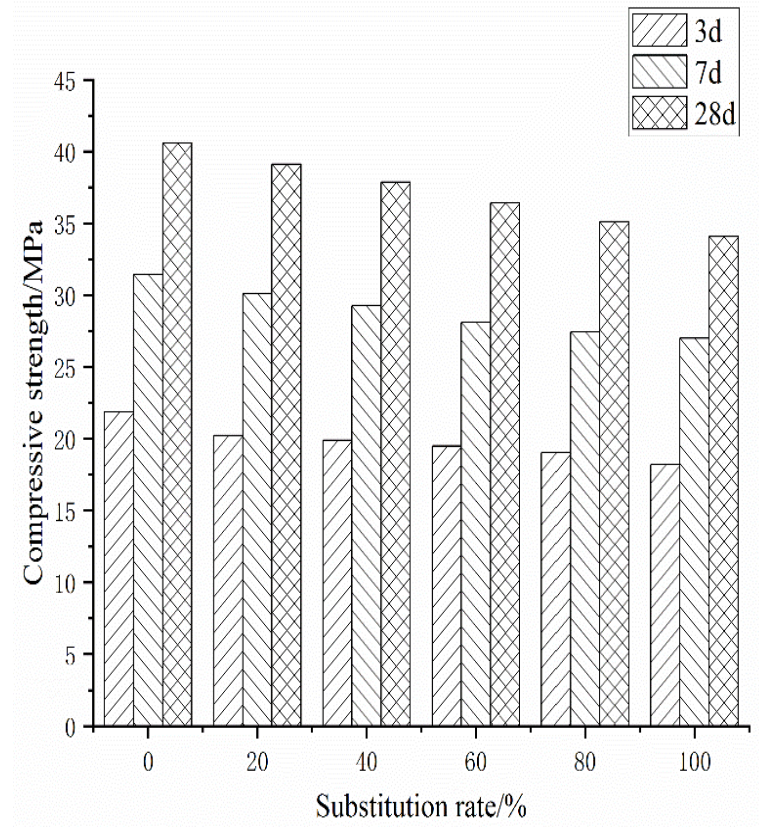

Fig. 3. Compressive strength of recycled aggregate concrete under different substitution rates.

\subsection{Splitting strength of concrete with different replacement rates of recycled aggregates}

In the mechanical properties of concrete, the splitting strength is an important index to characterize the cracking resistance of concrete, which can reflect the tensile properties of concrete. Figure 4 shows the 3 -day, 7-day and 28-day splitting strength of C30 concrete with different replacement rates of recycled aggregates. It can be seen from Figure 4 that the overall analysis shows that the splitting strength of recycled aggregate concrete decreases with the increase of the replacement rate of recycled aggregates. Compared with ordinary concrete, 3 days, 7-day and 28-day splitting strength of $100 \%$ recycled aggregate concrete decrease by $28.5 \%, 20.6 \%$ and $20.1 \%$, respectively. The reason is that the splitting strength characterizes the tensile capacity of concrete, and the bond strength between mortar in concrete after hydration has more influence on it.

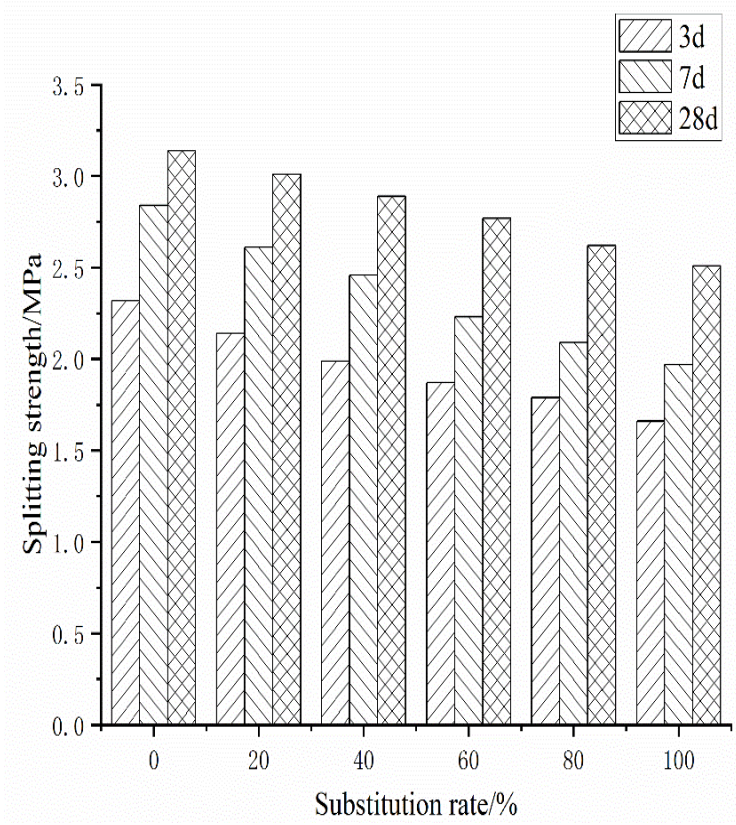

Fig. 4. Splitting strength of recycled aggregate concrete under different substitution rates.

\subsection{Cohesion force of concrete with different replacement rates of recycled aggregate}

In concrete, the cohesive force mainly depends on the binding of coarse aggregates formed by the cohesive component of cement paste and fine powder, which can be used to evaluate the shear strength of mixture. According to Mohr's theory formula (1), the bond strength of recycled aggregate concrete can be obtained, in which the splitting strength indirectly represents the tensile strength.

$$
\begin{aligned}
& f_{c}=2 c \cdot \tan (\pi / 4+\varphi / 2) \\
& f_{t}=2 c \cdot \cot (\pi / 4+\varphi / 2)
\end{aligned}
$$

Where: $f_{c}$ Compressive strength, $\mathrm{MPa}$

$$
\begin{aligned}
& f_{t} \_ \text {Tensile strength, } \mathrm{MPa} \\
& c-\text { Cohesion, } \mathrm{MPa} \\
& \varphi — \text { Internal friction angle, }\left(^{\circ}\right)
\end{aligned}
$$

\begin{tabular}{|c|c|c|c|c|c|c|c|}
\hline \multicolumn{2}{|c|}{$\begin{array}{c}\text { Substitution } \\
\text { rate } / \%\end{array}$} & 0 & 20 & 40 & 60 & 80 & 100 \\
\hline \multirow{3}{*}{$\begin{array}{l}\text { Cohesion } \\
\text { / MPa }\end{array}$} & $3 d$ & 3.54 & 3.29 & 3.15 & 3.02 & 2.92 & 2.78 \\
\hline & $7 d$ & 4.69 & 4.43 & 4.24 & 3.96 & 3.79 & 3.65 \\
\hline & $28 d$ & 5.64 & 5.43 & 5.23 & 5.02 & 4.80 & 4.62 \\
\hline
\end{tabular}

Table 3 Bond strength of recycled aggregate concrete with different replacement rates

Compared with ordinary concrete, the cohesion of recycled aggregate concrete decreases gradually under the curing cycle of 3 days, 7 days and 28 days. Compared with ordinary concrete, the 3-day bond strength of $100 \%$ recycled aggregate concrete decreases 
by $21.4 \%$, and the 7 -day bond strength decreases by $22.4 \%$, and the $28 \mathrm{~d}$ bond strength decreases by $18.1 \%$, seeing table 3 and fig. 5 , which is mainly caused by the inherent defects of recycled aggregates.

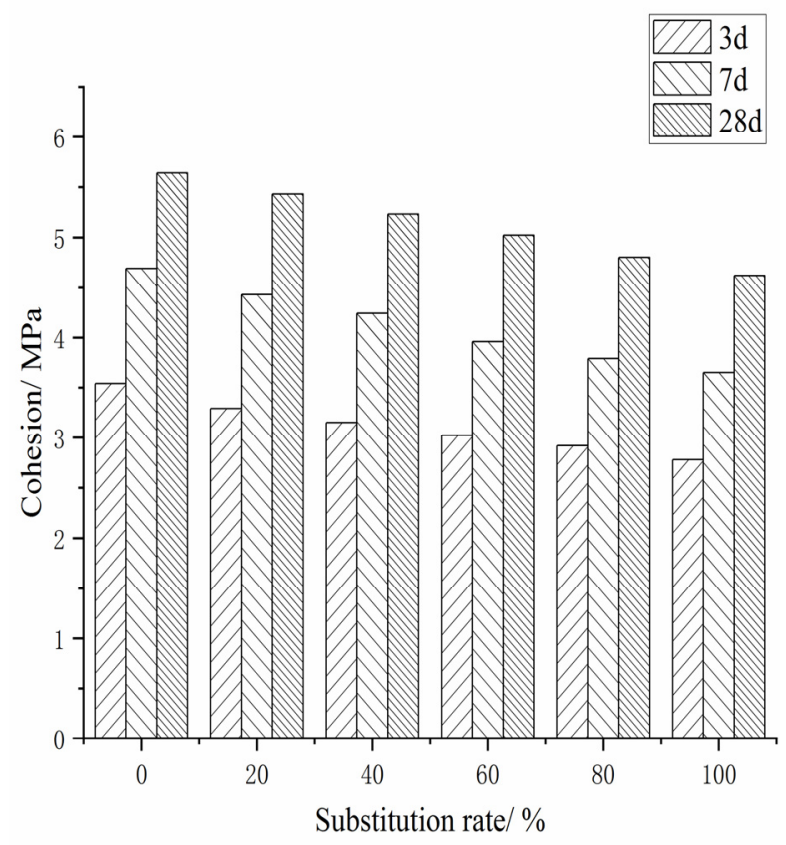

Fig. 5. Cohesion force of recycled aggregate concrete under different substitution rates.

Therefore, it can be seen from the analysis that there are two main factors affecting the strength of concrete. One is the compressive strength of the aggregates in the mixture; On the other hand, it is the cohesive force between the aggregates and the cement mortar in the base course mixture, so as to connect the coarse aggregates into a dense whole. The weakness of any of the above two factors will affect the compressive strength, splitting strength and bond strength of concrete. The recycled aggregates have weakened in both aspects, and its performance is also weaker than that of natural aggregate concrete.

\section{Conclusion}

Building solid waste is destructive to the environment, and the engineering application of recycled aggregate concrete provides a way for the supply of building materials for the treatment of building solid waste. In this paper, the influence of recycled aggregate replacement on the mechanical properties of concrete is studied. The 3-day, 7-day and 28-day compressive strength, splitting strength and cohesive force of ordinary concrete and recycled aggregate concrete with replacement rate of $20 \%, 40 \%, 60 \%, 80 \%$ and $100 \%$ are compared and analyzed through experiments. The results show that with the increase of replacement rate of recycled aggregates, the 3-day, 7-day and 28-day compressive strength, splitting strength and cohesive force of recycled aggregate concrete increase, and the splitting strength and bond strength decrease. When natural aggregates are replaced $100 \%$ recycled aggregates, the 28-day compressive strength, splitting strength and cohesive force of concrete are reduced by $16.1 \%, 20.1 \%$ and $18.1 \%$ respectively, but they all meet the requirements of strength index and have engineering application value.

\section{References}

1. J.Z. Xiao, K.J. Zhang, A. Akbarnezhad, Journal of Cleaner Production, 181 (2018)

2. C. Liu, Z.C. Ma, Liu Haoyun. Materials Reports 27, 4 (2017)

3. C. Marthong, A. S. Sangma, S. A. Choudhury, R.N. Pyrbot, S.L. Tron, L. Mawroh, G.S. Bharti, Structures, 11(2017)

4. C. Lima, A. Caggiano, C. Faella, E. Martinelli, M. Pepe, R. Realfonzo. Constr Build Mater, 47(2013)

5. ECKERT, MATTHIAS, OLIVERIRA, et al.,. Constr Build Mater, 133(2016)

6. G. Fathifazl, A. G. Razaqpur, O. B. Isgor, A. Abbas, B. Fournier, S. Foo, Cement and Concrete Composites, 10(2011).

7. L. Cheng, X.H. Deng, L.Y. Xue, J.Y. Wang. Journal of Xi'an Technological University, 40, 1 (2020)

8. X.Z. Li, Q.H. Wang, Y.Y. Wang, H. Zhang. Journal of Building Structures 40, 40(2019)

9. P. Folino, H. Xargay, Constr Build Mater, 56(2014) 